\title{
In Vitro $\alpha$-Amylase Inhibitory Activity of the Leaves of Thespesia populnea
}

\author{
R. Sangeetha and N. Vedasree \\ Department of Biochemistry, School of Life Sciences, Vels University, Chennai 600 117, India \\ Correspondence should be addressed to R.Sangeetha, sara_dna@yahoo.co.in
}

Received 26 November 2011; Accepted 10 January 2012

Academic Editors: S. Ceruti and K. Cimanga

Copyright ( $) 2012$ R. Sangeetha and N. Vedasree. This is an open access article distributed under the Creative Commons Attribution License, which permits unrestricted use, distribution, and reproduction in any medium, provided the original work is properly cited.

\begin{abstract}
Postprandial hyperglycemia is a prime characteristic of diabetes mellitus and has been a focus in the therapy for diabetes. One of the therapeutic approaches which involve decreasing hyperglycemia aims at inhibiting the enzyme $\alpha$-amylase. The leaves of $T$. populnea were studied for the presence of amylase inhibitors. The fractions obtained by successive fractionation using solvents of varying polarity were studied for the presence of primary and secondary metabolites. The total phenolic content of the different fractions was determined by HPLC and was correlated with their amylase inhibitory potential. Similarly, the protein content of the extracts was also estimated to understand the nature of the inhibitor present. This study shows that the leaves of T. populnea were effective in inhibiting $\alpha$-amylase, thereby proving to be potential hyperglycemic agents.
\end{abstract}

\section{Introduction}

Diabetic mellitus (DM) is a condition arising due to abnormal metabolism of carbohydrate, promoted by factors, namely, insulin deficiency and/or insulin resistance. This disorder prevails worldwide with its occurrence increasing at an alarming rate globally. Various complications encompass all the vital organs of the body as a consequence of the metabolic derangement in diabetes $[1,2]$. The treatment of DM is based on parenteral insulin and oral antidiabetic drugs. Oral hypoglycemic agents include sulphonylureas, biguanides, and other drugs like acarbose. These drugs have serious side effects and deleterious contraindications [2]. Hence herbal remedies having high therapeutic efficacy with minimal side effects are favoured. The antidiabetic agents from medicinal plants are very promising and traditionally acclaimed medicinal plants are being investigated for their antidiabetic potential $[3,4]$. Nearly 200 species of plant with hypoglycemic properties have been studied [5].

Highly processed, calorie-dense, nutrient depleted diet leads to exaggerated postprandial spikes in blood glucose and lipids that induces immediate oxidative stress. Induction of oxidative stress has been observed to increase in direct proportion to the increase in postprandial blood glucose level. Postprandial hyperglycemia culminates in type II diabetes mellitus and ensues in the formation of advanced glycation end products. These glycated products are the promoters of diabetic complications and aging [1]. Hence, one of the important therapeutic approaches for diabetes is to decrease hyperglycemia [6]. Herbal medicines with antidiabetic potential have different modes of action-mimic insulin, act on insulin secreting beta cells, or modify glucose utilization. Herbs which modify glucose utilization act by altering the viscosity of gastrointestinal contents, delaying gastric emptying, or delaying glucose absorption [2].

Absorption of glucose can be delayed by reducing the rate of digestion of starch. Inhibition of the mammalian alpha amylase enzyme in the intestine would delay the degradation of starch and oligosaccharides to monosaccharides before they can be absorbed. This would decrease the absorption of glucose and consequently reduce postprandial blood glucose level [5]. Therefore, screening of alpha-amylase inhibitors in medicinal plants has received much attention.

Thespesia populnea is a evergreen shrubby tree native to coastal areas of the Indian and Pacific Oceans. Its preferred scientific name is Thespesia populnea (L.) Sol.ex.Correa and belongs to family Malvaceae. The young leaves and green fruits are said to be edible. The bark and flowers possess 
astringent, hepatoprotective, antioxidant, antimicrobial, and anti-inflammatory activities. The antidiabetic effect of the bark of T. populnea has been well established [7]. However, the potential of the leaves of $T$. populnea has not been much studied, except for a study by Parthasarathy et al. [4], using the methanolic extract of the T. populnea leaves. The present investigation was initiated to screen the leaves of $T$. populnea for amylase inhibitory activity and correlate it with the polyphenolic content of the leaf extracts.

\section{Materials and Methods}

2.1. Collection of Plant Material. The plant material (leaves) was collected from Chennai, India in January, 2011. The plant material was duly authenticated by Dr. Jayaraman Director at National Institute of Herbal Science (PARC), Chennai (Voucher number: PARC/2011/742).

2.2. Preparation of Extract. The leaves were air-dried, pulverized by grinding using mortar and pestle. Thereafter, the coarse powder of air-dried leaf were subjected to successive solvent extraction by maceration for $72 \mathrm{~h}$ using solvents of increasing polarity in petroleum ether, chloroform, ethyl acetate, and methanol. Filtered contents were distilled, evaporated, air-dried, freezed, and stored in air tight plastic containers. The respective extractive yields of the extracts were calculated.

2.3. Analysis of Primary Metabolites. The primary metabolites like carbohydrates, total proteins, and lipid contents were quantified. Carbohydrates were quantified by the method of McCready et al. [8], proteins by Lowry et al. [9], and lipids by Zak et al. [10].

2.4. Analysis of Secondary Metabolites. Secondary metabolites like tannins, phenols, and flavonoids were quantified in all the individual extracts.

2.4.1. Estimation of Total Phenols. The total phenolic content of the purified fractions was determined using the Folin Ciocalteau method reported by Singleton and Rossi [11]. Briefly, to $0.1 \mathrm{~mL}$ of the extract, $0.5 \mathrm{~mL}$ of Folin Ciocalteau reagent and $5.0 \mathrm{~mL}$ of sodium carbonate were added. The reaction mixture was allowed to stand for $30 \mathrm{~min}$ and the absorbance was measured at $640 \mathrm{~nm}$. Gallic acid was used as the standard. Extracts were analysed in triplicates.

2.4.2. Estimation of Total Tannins. Total tannins were estimated by the method of McDonald et al. [12]. $1 \mathrm{mg}$ of each of the extracts was weighed and dissolved in $10 \mathrm{~mL}$ of methanol water $(7: 3)$. To this $0.5 \mathrm{~mL}$ Folin's phenol reagent $(1: 2)$ followed by $5 \mathrm{~mL}$ of $3.5 \%$ sodium carbonate was added and the color intensity was read at $640 \mathrm{~nm}$ after $5 \mathrm{~min}$. Extracts were analysed in triplicates.

2.4.3. Estimation of Total Flavanoids. The total flavanoid content of the purified fractions was determined using the aluminium chloride method reported by Zhishen et al. [13] To $1 \mathrm{~mL}$ of the extract, $4 \mathrm{~mL}$ of $\mathrm{H}_{2} \mathrm{O}$ and $0.3 \mathrm{~mL}$ of $\mathrm{NaNO}_{2}$ (5\%) were added. After $5 \mathrm{~min}, 0.3 \mathrm{~mL}$ of $\mathrm{AlCl}_{3}(10 \%)$ was added followed by $2 \mathrm{~mL}$ of $\mathrm{NaOH}(1 \mathrm{M})$. The final volume was made up to $10 \mathrm{~mL}$ with $\mathrm{H}_{2} \mathrm{O}$ and the solution was mixed well. The absorbance was read at $510 \mathrm{~nm}$. Quercetin was used as the standard. Extracts were analysed in triplicates.

2.5. Estimation of Total Phenols by HPLC. The total phenolics in both the extracts were detected using a suitable analytical column with the stationary phase Octadecylsilyl silica and mobile phase [A—phosphoric acid: water $(0.5: 99.5 \mathrm{v} / \mathrm{v})$ B-acetonitrile]. Gallic acid, p-coumaric acid, ellagic acid, ferulic acid, mandelic acid, and vanillic acid were used as reference compounds. $20 \mu \mathrm{L}$ of the test solution and reference solutions were injected into the column. The detector used for analysis was a UV detector, set at $220 \mathrm{~nm}$ with a flow rate of $1.0 \mathrm{~mL} / \mathrm{min}$.

2.6. Assay of Amylase Inhibition. In vitro amylase inhibition was studied by the method of Bernfeld [14]. In brief, $100 \mu \mathrm{L}$ of the test extract was allowed to react with $200 \mu \mathrm{L}$ of $\alpha$ amylase enzyme (Hi media $\mathrm{Rm} 638$ ) and $100 \mu \mathrm{L}$ of $2 \mathrm{mM}$ of phosphate buffer ( $\mathrm{pH}-6.9)$. After 20-minute incubation, $100 \mu \mathrm{L}$ of $1 \%$ starch solution was added. The same was performed for the controls where $200 \mu \mathrm{L}$ of the enzyme was replaced by buffer. After incubation for 5 minutes, $500 \mu \mathrm{L}$ of dinitrosalicylic acid reagent was added to both control and test. They were kept in boiling water bath for $5 \mathrm{~min}$. The absorbance was recorded at $540 \mathrm{~nm}$ using spectrophotometer and the percentage inhibition of $\alpha$-amylase enzyme was calculated using the formula

$$
\text { Inhibition }(\%)=100\left(\frac{\text { control }- \text { test }}{\text { control }}\right) \text {. }
$$

Suitable reagent blank and inhibitor controls were simultaneously carried out.

2.7. Activity Staining of Amylase. Activity staining of amylase was done according to the method of Scandalios [15]. The gel consisted of $1 \%$ agar in $0.4 \mathrm{M}$ phosphate buffer of $\mathrm{pH}$ 7.5. The plant extracts $(1 \mathrm{mg} / \mathrm{mL})$ that were preincubated with the enzyme were loaded in to different wells. Untreated enzyme served as a positive control in a separate well. The buffer used in the gel was also used in the electrode compartments. A stabilized current of $100 \mathrm{~V}$ was passed through the gel for $2 \mathrm{~h}$ at $4^{\circ} \mathrm{C}$. For visualization of the amylase bands the tray was immersed in $0.5 \%$ soluble starch and incubated at $37^{\circ} \mathrm{C}$ for $30 \mathrm{~min}$. The excess starch was then washed and the gel was flooded with iodide potassium iodide solution for $1 \mathrm{~min}$. Colorless bands against a deep blue background indicated amylase activity.

\section{Results and Discussion}

Hyperglycemia has been a classical risk in the development of diabetes and the complications associated with diabetes. Therefore control of blood glucose levels is critical in the 


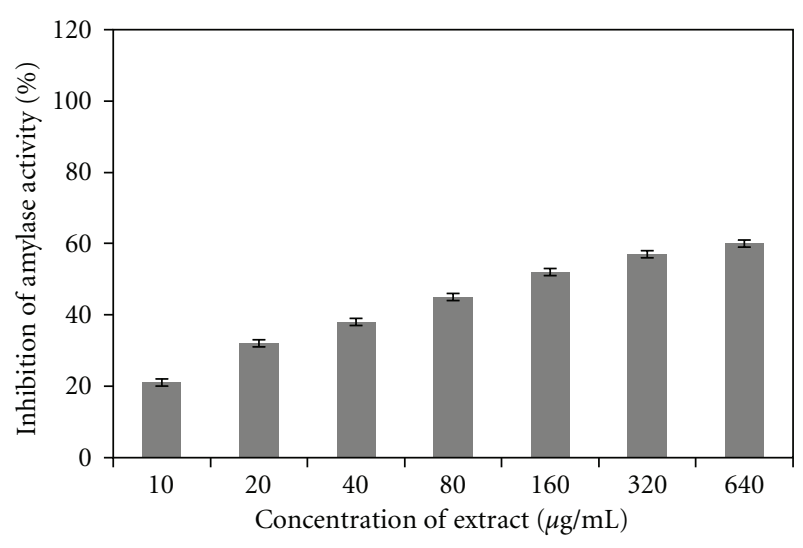

(a) PETP

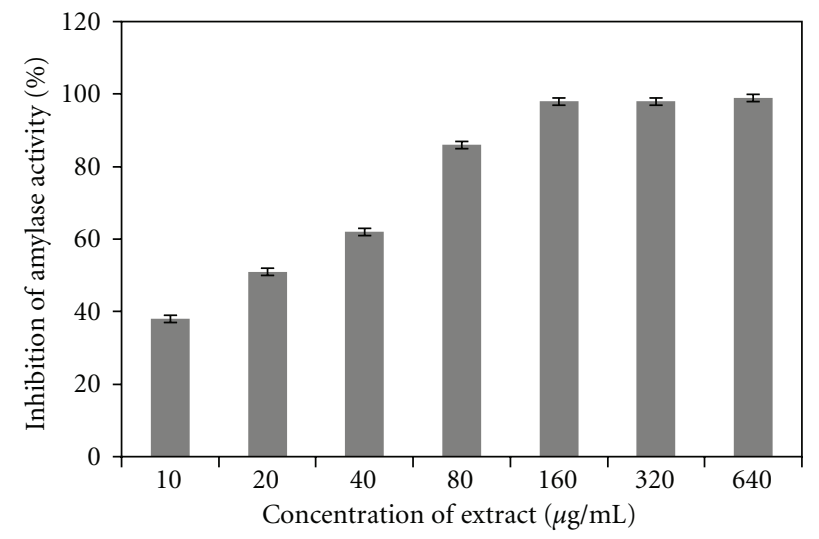

(c) EATP

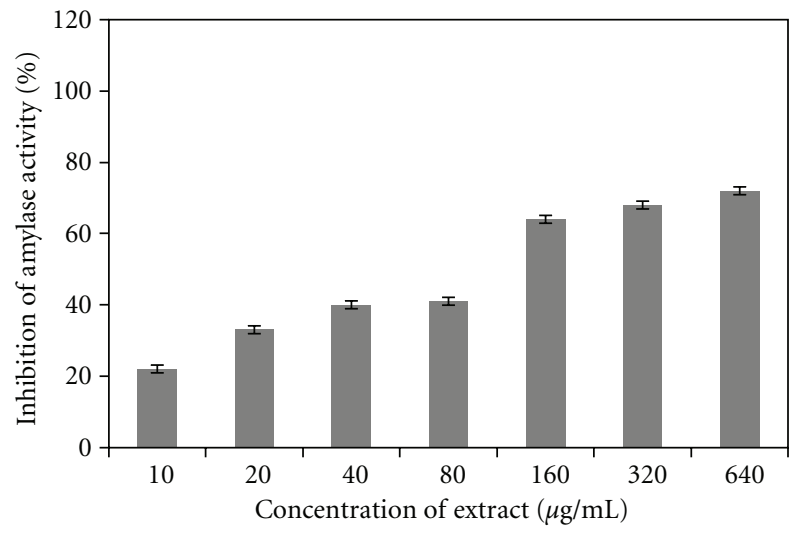

(b) CTP

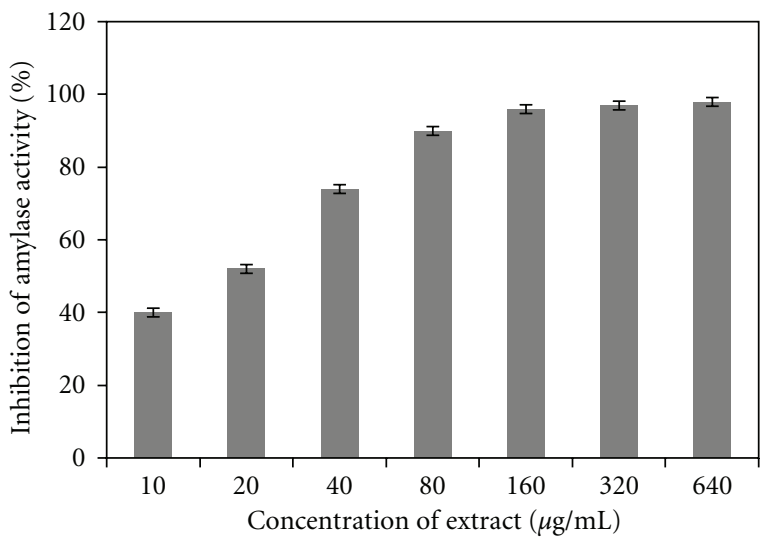

(d) MTP

FIGURE 1: Amylase inhibitory activity of the extracts of the leaves of T. populnea.

early treatment of diabetes mellitus and reduction of macroand microvascular complications. One therapeutic approach is the prevention of carbohydrate absorption after food intake, which is facilitated by inhibition of enteric enzymes including $\alpha$-glucosidase and $\alpha$-amylase present in the brush borders of intestine.

In this study, the $\alpha$-amylase inhibitory activity of the leaves of T. populnea was investigated. The inhibitory effect of petroleum ether (PETP), chloroform (CTP), ethyl acetate (EATP), and methanol (MTP) extracts was analysed. The percentage inhibition of $\alpha$-amylase by the extracts of T. populnea was studied in a concentration range of $10-640 \mu \mathrm{g} /$ $\mathrm{mL}$. Of the four extracts, EATP and MTP were comparatively effective than PETP and CTP in inhibiting $\alpha$-amylase (Himedia RM638).

The $\mathrm{IC}_{50}$ of PETP and CTP was 100 and $120 \mu \mathrm{g}$, respectively, and methanol extracts was $20 \mu \mathrm{g}$. The EATP and MTP exhibited a maximum inhibition of $98 \%$ at $50 \mu \mathrm{g} / \mathrm{mL}$ concentration. The percentage inhibition of all the extracts was not dose dependent (Figures 1(a)-1(d)).

The inhibitory effect of all the extracts was also analysed using amylase zymogram. The effects of the inhibitor of two different concentrations were studied. The concentration chosen for EATP and MTP was $10 \pm \mathrm{IC}_{50}$ and that chosen for PETP and CTP extracts was $20 \pm \mathrm{IC}_{50}$. Complete inhibition of amylase was observed when the concentrations of the extracts were above the $\mathrm{IC}_{50}$ value. The activity of the extracts was compared with the enzyme control which exhibited a distinct achromatic band against a dark blue background on the agar gel. At concentrations below the $\mathrm{IC}_{50}$ value, faint colorless bands could be observed with EATP and MTP and this indicates partial inhibition of the $\alpha$-amylase (Figure 2). This indicates inhibition of amylase activity and utilization of starch substrate.

Enzyme inhibitors may be proteinaceous or nonproteinaceous in nature. Hence the inhibitory activity of the extracts was correlated with their protein and polyphenolic content. The phenolic content of the extracts was also studied by HPLC. The total phenolic content of MTP was $6.98 \mathrm{mg}$ and that of EATP was $5.26 \mathrm{mg}$. The quantity of total polyphenols in PETP and CTP was low (2.88 and $1.89 \mathrm{mg}$, resp.) when compared to MTP and EATP. The amylase inhibitory potential of EATP was greater than that of MTP, as indicated by the zymogram analysis of amylase. Thus there was no correlation between the total phenolics present in the extract and the amylase inhibitory activity of the extracts.

The presence of phenolic acids in MTP was observed in the decreasing order of concentration of ferulic acid > vanillic acid > ellagic acid > coumaric acid $>$ gallic acid. The phenolic acids in the EATP of T. populnea were in the following order of decreasing concentration ellagic acid $>$ coumaric acid $>$ vanillic acid $>$ gallic acid (Figures $3(\mathrm{a})$ and $3(\mathrm{~b})$ ). 


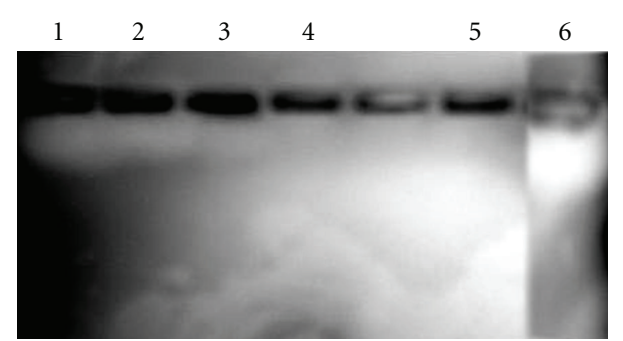

FIgURE 2: Zymogram study of amylase activity. Lane 1: EATP, lane 2: MTP, lane 3: CTP, lane 4: PETP, lane 5: negative control, lane 6: positive control.

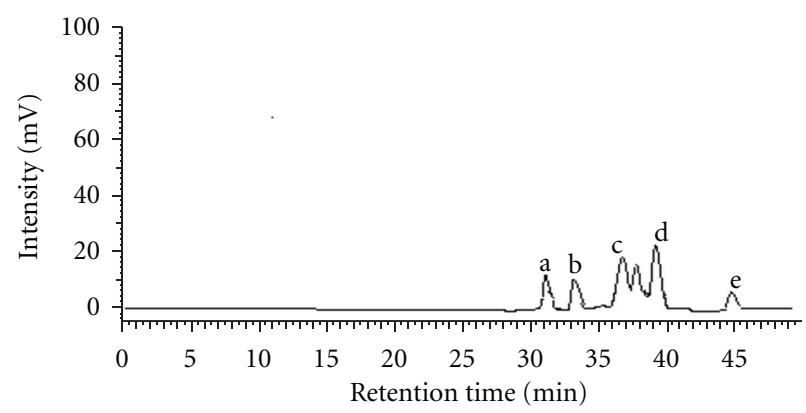

(a) MTP

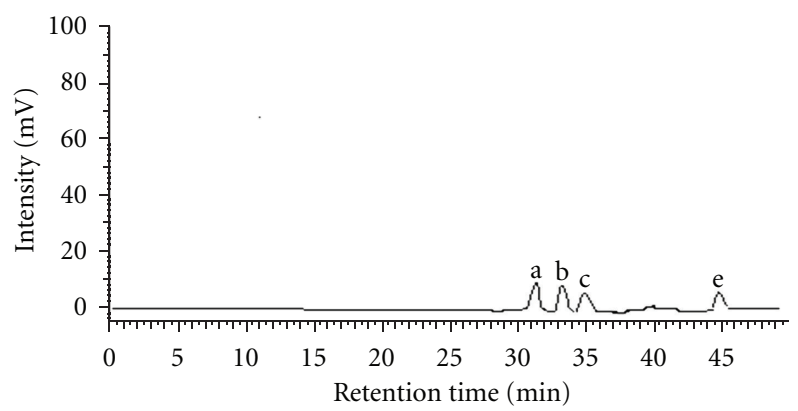

(b) EATP

Figure 3: HPLC profile of the extracts of T. populnea leaves. The phenols present in the extracts were (a) ellagic acid, (b) coumaric acid, (c) vanillic acid, (d) ferulic acid, and (e) gallic acid.

The protein content was found to be high in EATP and low in CTP. The protein content was found in the following order: EATP > MTP > PETP > CTP (data not shown). The protein and phenol analysis of all the four extracts showed that the alpha-amylase inhibitor present in the leaves of $T$. populnea may be proteinaceous in nature.

\section{Conclusion}

The current study was to evaluate the amylase inhibitory potential of the leaves of T. populnea. The extent of inhibition by the different extracts was compared to the total polyphenolic and protein content of the extracts. The methanolic and ethyl acetate extract of the leaves was found to possess potent amylase inhibitor. The leaves of T. populnea have been also proved to possess antioxidant activity [4]. Thus this study confirms that the leaves of T. populnea can mitigate postprandial hyperglycemia and ameliorate oxidative stress and therefore assist in combating diabetic complications.

\section{References}

[1] K. T. Ashok, S. Madham, A. B. Shaik, Z. S. Amtul, B. A. Sachin, and M. Kuncha, "Identification of proglycemic and antihyperglycemic activity in antioxidant rich fraction of some common food grains," International Food Research Journal, vol. 18, no. 3, pp. 883-891, 2011.

[2] K. A. Wadkar, C. S. Magdum, S. S. Patil, and N. S. Naikwade, "Anti-diabetic potential and indian medicinal plants," Journal of Herbal Medicine and Toxicology, vol. 2, no. 1, pp. 45-50, 2008.

[3] V. Babu, T. Gangadevi, and A. Subramanian, "Antihyperglycemic effect of Cassia keinii leaf extract in glucose feed normal rats and alloxam induced diabetic rats," Indian Journal of Pharmacology, vol. 34, no. 6, pp. 409-415, 2002.

[4] R. Parthasarathy, R. Ilavarasan, and C. M. Karrunakaran, "Antidiabetic activity of Thespesia Populnea bark and leaf extract against streptozotocin induced diabetic rats," International Journal of PharmTech Research, vol. 1, no. 4, pp. 10691072, 2009.

[5] K. Karthic, K. S. Kirthiram, S. Sadasivam, B. Thayumanavan, and T. Palvannan, "Identification of $\alpha$ amylase inhibitors from Syzygium cumini Linn seeds," Indian Journal of Experimental Biology, vol. 46, no. 9, pp. 677-680, 2008.

[6] M. B. Narkhede, "Investigation of in vitro $\alpha$-amylase and $\alpha$ glucosidase inhibitory avtivites of polyherbal extract," International Journal of Pharmaceutical Research and Development, vol. 3, no. 8, pp. 97-103, 2011.

[7] M. Vasudevan, K. K. Gunnam, and M. Parle, "Antinociceptive and anti-inflammatory effects of Thespesia populnea bark extract," Journal of Ethnopharmacology, vol. 109, no. 2, pp. 264270, 2007.

[8] R. M. McCready, J. Guggolz, V. Silviera, and H. S. Owens, "Determination of starch and amylose in vegetables," Analytical Chemistry, vol. 22, no. 9, pp. 1156-1158, 1950.

[9] O. H. Lowry, N. J. Rosebrough, A. L. Farr, and R. J. Randall, "Protein measurement with the folin Phenol reagent," The Journal of Biological Chemistry, vol. 193, no. 1, pp. 265-275, 1951.

[10] B. Zak, A. J. Boyle, and A. Zlatkis, "A new method for the direct determination of serum cholesterol," The Journal of Laboratory and Clinical Medicine, vol. 41, no. 3, pp. 486-492, 1953.

[11] V. L. Singleton and J. A. Rossi, "Colorimetry of total phenolics with phosphomolybdic-phosphotungstic acid reagents," American Journal of Enology and Viticulture, vol. 16, no. 3, pp. 144-158, 1965.

[12] S. McDonald, P. D. Prenzler, M. Antolovich, and K. Robards, "Phenolic content and antioxidant activity of olive extracts," Food Chemistry, vol. 73, no. 1, pp. 73-84, 2001.

[13] J. Zhishen, T. Mengcheng, and W. Jianming, "The determination of flavonoid contents in mulberry and their scavenging effects on superoxide radicals," Food Chemistry, vol. 64, no. 4, pp. 555-559, 1999.

[14] P. Bernfeld, "Amylase, $\alpha$ and $\beta$," in Methods in Enzymology, S. P. Colowick and N. O. Kaplan, Eds., pp. 149-158, Academic Press, New York, NY, USA, 1955.

[15] J. G. Scandalios, "Isozymes in development and differentiation," Annual Review of Plant Physiology, vol. 25, pp. 225-258, 1974. 

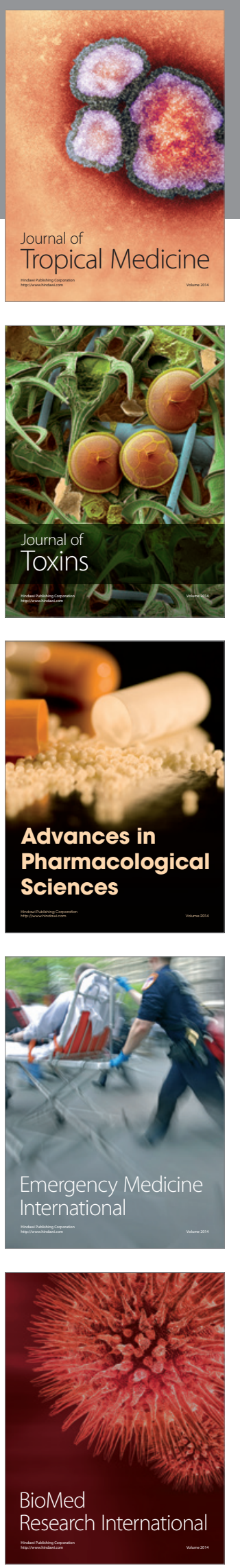
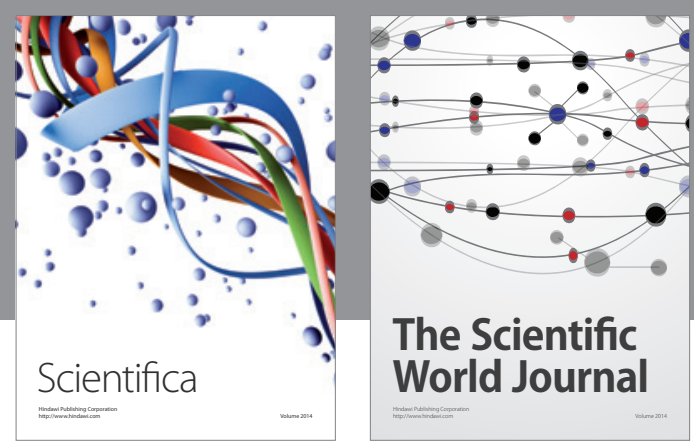

The Scientific World Journal
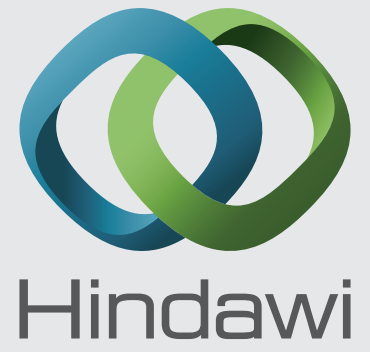

Submit your manuscripts at

http://www.hindawi.com
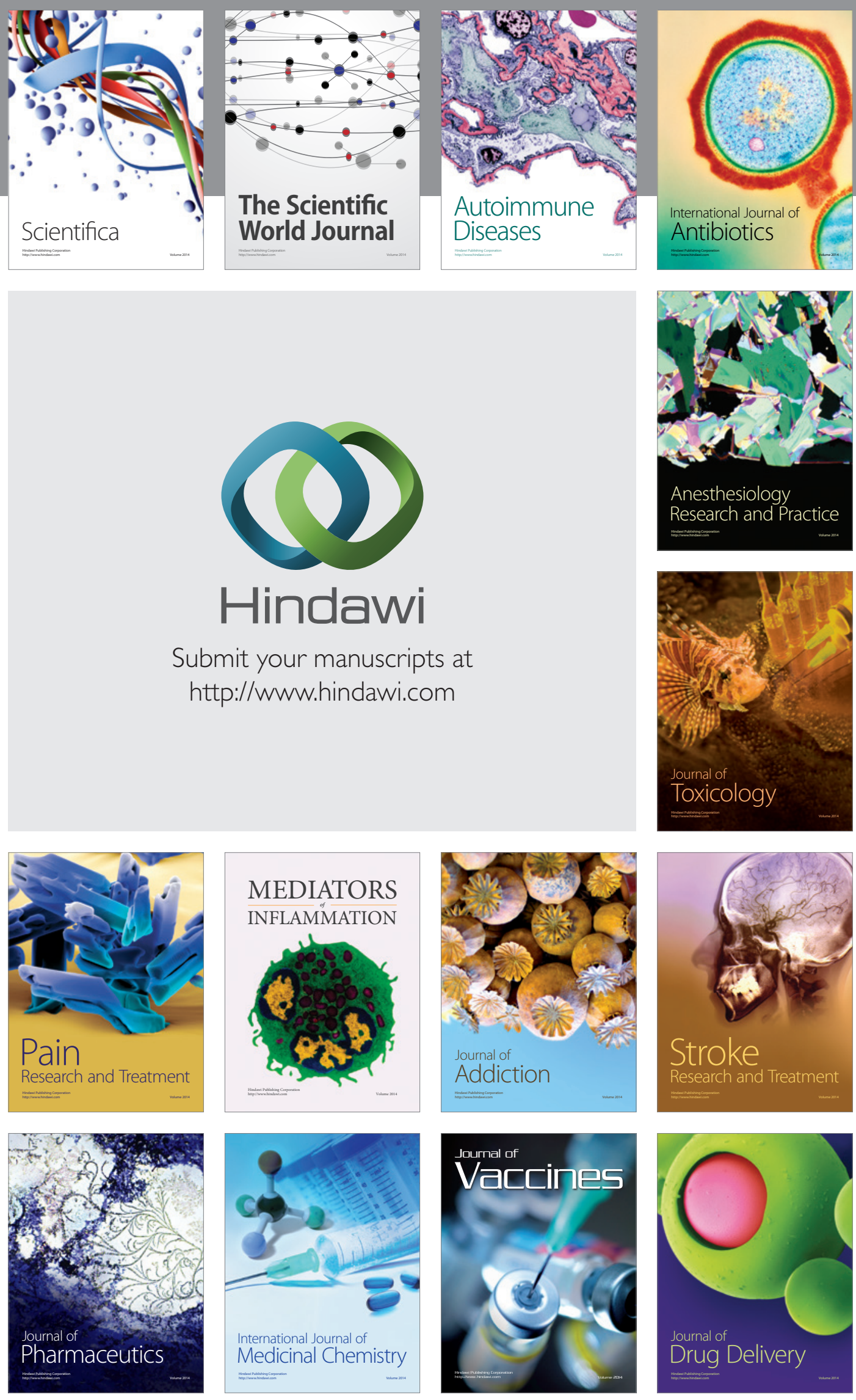